\title{
BECOMING ENTREPRENEUR IN ROMANIA: THE ROLE OF ENTREPRENEURSHIP EDUCATION
}

\author{
Ioana Gabriela Domilescu ${ }^{1}$, Andrei Alexandru Tărăbîc ${ }^{2 *}$ \\ ${ }^{1}$ West University of Timisoara, Teacher Training Department \\ ${ }^{2}$ West University of Timisoara, Faculty of Economics and Business Administration \\ V. Pârvan, No. 4, Timișoara, Romania \\ * Corresponding author. E-mail: andrei.tarabic@e-uvt.ro
}

\begin{abstract}
The present study (based on the analysis of 26 interviews) aims to identify the impact of formal entrepreneurship education on the professional life of entrepreneurs and ways of improving entrepreneurship education in secondary, high school and higher education, the findings showing that formal entrepreneurship education has little influence on becoming an entrepreneur.
\end{abstract}

Keywords: entrepreneurship education, entrepreneurial competence, formal education, EntreComp model.

\section{Introduction}

Since 2006, the European Commission has stressed that education and training should support the development of entrepreneurship. Most European educational policy documents define "entrepreneurship" as " initiative", "a person's ability to turn ideas into action", "creativity, innovation and risk taking", "the ability to prepare and manage projects in order to achieve the objectives". Entrepreneurship as a competence applies to all spheres of life because it allows citizens to personally develop, actively contribute to social development, enter the labor market as an employee or on their own, and initiate or expand enterprises that may have a cultural, social or commercial ground. Entrepreneurship education is growing worldwide, but key educational and didactic issues remain.

\section{Methodological Design}

This research is based on the narrative and thematic analysis of 26 semi-structured interviews conducted between $2019-2020$ with the winners of the business plans submitted in the competition held within the project Start UP Banat (http://startupbanat.projects.uvt.ro/).

The interviews, conducted by an interdisciplinary team of researchers from the West University of Timișoara, were part of a larger project which also included a training program meant to develop entrepreneurial competences and those necessary for writing and implementing a business plan. Within the project, a business plan competition was held and 36 business plans were selected in order to benefit from financing. The fields of activity chosen by the entrepreneurs participating in the competition are diverse: gardening and landscaping, restaurants, ecological car washing, online stores, beauty and health promotion services, artistic activities, translations, consulting, rental of electric scooters and mopeds and cars, fashion, online media organizing weddings and a driving school.

The main goal of the research was to reveal the way in which entrepreneurship education from secondary and highschool, but, also, from higher education impacted on the decision of new entrepreneurs on taking this path and to identify ways in which entrepreneurship education could be improved and become more effective. Although the project funded 36 business plans, the interviews were conducted with only 26 of the beneficiaries, the main cause being the lack of availability of the others to participate, but also the fact that we reached the saturation of data.

The semi-structured interview guide was based on 14 questions concerning: the educational and professional route of the respondents; representations about the concept of entrepreneurial education; educational experiences regarding entrepreneurial education; the evolution as entrepreneurs (the role of formal education); educational experience from the training program (Start UP Banat Project); future interest in entrepreneurial training programs; personal perception on the role of formal education in the development of entrepreneurial skills. To these pre-set questions, others were added during the course of interviews regarding educational and life pathways, business experiences of the people who won the funding within the project.

Given the size of the interviews, their purpose and the manner they were conducted (face to face or online), we chose a qualitative approach to analyzing the data. "Narrative analysis focuses its attention on subjectivity, which is the manner in which each of the interviewees portray themselves as related to social structure" [1].

\section{Discussions}

12 males and 14 females answered to the interviews, the vast majority coming from urban areas 
(about $88 \%$ ) and only 3 from rural areas (about 12\%). One young student was 20 years old, 8 young entrepreneurs were between 20 and 30 years old, 8 between 30 and 40 years old, 4 of the interviewees were between 40 and 50 years old, and 3 entrepreneurs were 51 and 52 years old, respectively. A noteworthy aspect is the fact that more than half of the interviewees (approximately 57\%) were people who have changed their residence, coming from their home towns in Timisoara or in other localities in the west of the country (Lugoj, Arad, Caransebeș).

Regarding the educational path of the respondents, 22 of them (approximately 77\%) graduated from theoretical high schools and only $23 \%$ from vocational high schools (sports, music, health, pedagogy) without currently practicing in that profession, with one exception (a young lady has a Bachelor's degree in arts and another in Economics and now she won funding from Start UP with a business plan aimed at setting up a ballet studio).

One young entrepreneur is still student, two entrepreneurs have only high school education, 21 of them have a university degree and two of them have two higher educational degrees in different fields: economics, law, technical specializations, agriculture, dentistry, political sciences, philology, sociology, psychology. Approximately $57 \%$ of those interviewed have a master's degree and only one person has a doctorate in science (in the same field in which he has a bachelor's and master's degree).

12 of the respondents, approximately $46 \%$, are people who have been employed and worked since their student years and half of the interviewees also participated in volunteer activities organized by student associations or other NGOs, experience that helped them to form part of their entrepreneurial skills, according to their statements). One of the respondents states that " $I$ was hired from the first year of college and in 3 years I changed 4 or 5 jobs with different working hours", the experience helping her to become more "confident and brave". The youngest of the entrepreneurs, a 20 -year-old student, was hired since high school, the experience making him aware that "as an employee I earned very little money" and stimulating him to create his own business.

Among the entrepreneurs we also meet people whose educational and professional paths interestingly combine, due to the diversity of the fields they have worked in and studied:

- a young entrepreneur graduated from a confessional high school, studied dentistry (practicing only 5 years in this field), founded a Romanian-Swedish partnership in the field of carpentry design with 12 employees, and won funding from the Start UP project for a photo-video studio.

- a 29-year-old woman graduated from a computer science high school, studied law; in the first year of college she worked as an accountant in a restaurant, in the second year of college she opened her own business in the field of employment placement in Germany, in the third year of college she started working in the field of consulting on European funds; now she obtained financing through Strat UP for a business plan in the field of cosmetology;

- a 51-year-old woman, graduated from a theoretical high school and she has post-secondary education in various fields (computer science, tailoring, pastry, kitchen); she worked as a clerk for a construction company; now she obtained financing through Strat UP for a business that offers interior and exterior printing services for buildings.

- a 44-year-old lawyer, graduated from a sanitary high school and now she studies social work; the funding from Start UP is for a business plan that aims to provide educational services for children, including those in placement or with special educational needs.

The vast majority of entrepreneurs associate the concept of entrepreneurship education with the idea of running a business. Some of the entrepreneurs take into account the more practical elements involved in defining entrepreneurial education: "learning not to make mistakes", "entrepreneurial education tells you what to avoid", "interaction with customers", "developing a thinking taking risks, accepting challenges and finding optimal solutions for running a business", "efficient management of your own business", "entrepreneurship education is not only about making money, but also about how you can keep it", "entrepreneurship education helps you to opens horizons for others".

Most of those who won funding through Start up Banat say that they did not benefit of entrepreneurship education in compulsory formal education. Of the 26 respondents, only 9 remember having discussed issues related to entrepreneurship in high school (in economics or civics). The most appreciated (maintained in the longterm memory) aspects related to entrepreneurship education during high school are: projects and business plans, business ideas competitions, making a personal and family budget. There are also graduates whose formal education has shaped their attitudes and behaviors and that they currently consider beneficial in terms of success as an entrepreneur: a theological high school graduate mentions that "trust, optimism, honesty, and fairness help me become a good entrepreneur".

We identify elements of entrepreneurial education in the curricula of different specializations in higher education: a part of our respondents have a Bachelor's Degree in Economics, where aspects related to entrepreneurship education were explicitly discussed; entrepreneurship education also appears when studying Law (commercial law, contracts), Philology (management, marketing), Sociology (human resources, marketing, leadership styles) and Political Sciences (European funds). It is noteworthy that all those who benefited in one form or another of entrepreneurship education claim that it was useful in various situations 
that arose either at work, or in the emergence of the business idea, or in writing and implementation of the business plan.

Regarding entrepreneurship education in school, some entrepreneurs say that "it is completely missing from school" (high school graduate 2008) or "if I had done something in this field in high school, I would certainly have changed my profileleducational and professional path". Entrepreneurship education, studied in high school, in the 10th grade at all profiles and specializations, one hour each week is compulsory in the Romanian educational system since 2004, meaning that most of our interviewees did not study this subject as part of compulsory education in high school. Many different combinations of approaches meant to integrate entrepreneurship education into general education appear within the educational reforms of European countries. Most European countries explicitly recognize entrepreneurship education at least to some degree in primary and secondary education. Unfortunately, this is not the case in Romania.

Another aspect addressed in the interview was the role of formal education in the decision of becoming an entrepreneur. The emergence of the idea of becoming an entrepreneur / having one's own business is strongly influenced by the personal path of each interviewee. Three ladies state that "I always wanted to have my own business" or "since I was a child", "that's how I grew up in the house, with the principle: Don't sell your time to someone else". Three of the respondents state that this idea appeared in high school; for seven of them the idea of having their own business has emerged in recent years (2015 - 2018); only for one of the respondents the idea of having a business is 10 years old; two of the entrepreneurs took it into account after enrolling in the program run by Start UP Banat; for two of the entrepreneurs this idea appeared and flourished during the activities organized by NGOs.

Regarding the role of school (both high school and university studies, but also extracurricular activities mediated by educational institutions) in the emergence of business idea, more than half of the interviewed entrepreneurs say that school positively influenced the emergence of the business idea, especially through undergraduate and master's studies and by participating in activities organized by NGOs in collaboration with the university; there are also entrepreneurs who remember high school teachers who stimulated their entrepreneurial spirit.

Statistics at European level indicate that Romania gives little importance to entrepreneurship education, so that less than $10 \%$ of those who have initiated and developed a business also have a theoretical basis in this respect, compared to the European average of $30 \%$. The employment rate of the population aged 20-64 in Romania (63.9\% in 2013) is lower than the EU average $(68.5 \%$ in 2012), with the national target being $70 \%$ by 2020 .

Most entrepreneurs mention as the main "engine" in the emergence and development of their business idea their personal desire to accumulate new knowledge, to learn, to develop, to fulfill a dream ("I had entrepreneurial spirit since I was a little girl", "I knew from the second year of college that I want to be an entrepreneur"), but also social responsibility and positive community impact (one of the respondents already manages a business where he employs people from risk categories).

Some respondents mention well-known successful entrepreneurs and motivational speakers as having a positive influence on the emergence and development of their business idea (Brian Tracy, Tony Robbins, Cristian Onețiu, Lorand Soares Szasz, Jay Z, Seth Golding, Bill Gates). A significant part of the respondents mention that their entrepreneurial spirit was also positively influenced by the teachers they had either in high school ("an exceptional math teacher"), or in faculty, but also by the training they participated within the project Start up Banat.

Almost all participants appreciated the usefulness of all the activities within the training program and their role in the design of the business plan, stating that "we had accessible, useful, relevant courses", "the courses were well structured and presented", "there were engaging, interactive courses", "I appreciated the openness, interactivity, freedom of the courses" some of the students also mentioning inspirational teachers and the fact that they "learnt to think out of the box ". Even though they have already received the funding and started their business, half of the interviewees expressed their interest in participating in other educational programs for entrepreneurs.

Regarding the characteristics of a successful entrepreneur, the answers, respectively the qualities are diverse, the most frequently mentioned being: perseverance; courage (high level of aspirations); respect /fairness (towards customers and employees); permanent development/continuous education. To these aspects are added the following: flexibility/adaptability, resistance to working under pressure; failure management, ability to make assumed, fast and efficient decisions; professional empathy; ability to solve problems; passion, motivation and optimism / positive thinking. Interesting is the statement that a successful entrepreneur must be "a little humble" (thereby respondents understanding the absence of arrogance and the presence of common sense), and to "treat people at the same level, without airs of superiority."

\section{Conclusions and Recommendations}

The majority of entrepreneurs associate the concept of entrepreneurship education with the idea of running a business and did not benefit of entrepreneurship education in compulsory formal education, but a significant part of the respondents stated that their entrepreneurial spirit was positively influenced by the teachers they had at various levels of the education system. 
Addressing the above mentioned issues, this article advances two types of recommendations: a set of suggestions made by the entrepreneurs themselves who found time and availability to reflect on the role of formal education in their professional development and a set of proposals resulting from the analysis of the literature in the field.

When invited to offer their perspective on how to improve the contribution of formal education to the development of entrepreneurial skills, the answers differ and refer both to secondary and high school and higher education:

- for higher education: a module of entrepreneurial skills that students have the opportunity to follow in parallel with undergraduate and master's studies, regardless of specialization; courses addressing the design of medium and long-term activities and risk management (anticipation of non-ok situations that may arise), business scaling.

- for secondary and high school: introducing entrepreneurship education courses (even with a different name) in secondary schools with focus on topics related to budget, sales, profit; introducing in compulsory education subjects as financial education, work legislation, school and career counseling, along with identifying affinities / talents / skills that would facilitate success as an entrepreneur; introducing entrepreneurial projects from primary education (specific to the age, possibly interdisciplinary) and continuing them in secondary on topics related to financial responsibility, sales, work, profit; carrying out entrepreneurial projects for the benefit of the school by involving the local community as the main beneficiary of those projects; other non-formal education activities carried out in school.

- for both secondary, high school and higher education: information and counseling regarding the opportunities and benefits of developing a business; promoting failure management: "If you made a mistake it is not the end of the world", "We must be aware that we do not always make the best decisions, but we must always be open to improve and optimize everything we do"; changing the approach on entrepreneurship education in order to teach it not incisively, formally, compulsorily, but rather in the form of personal development activities and "developing the necessary mindset, a proactive mind that can see things as a whole"; involving successful entrepreneurs in formal university or secondary and high school education (debates, conferences, courses and events with successful entrepreneurs in order to inspire students); promoting and seriously consolidating volunteering among students and young people, due to its potential of leading to the formation of responsible attitudes towards money, teamwork, conflict management / unforeseen situations; increasing learning motivation through specific activities (some entrepreneurs say that "today's young people no longer want to work", "school does not stimulate children's desire to learn"); promoting and encouraging reading books in the field of entrepreneurship, many of which can contribute to the personal development of students.

These comments made by our respondents from personal experience are in line with those stipulated in the documents of the European Commission stating that it is difficult to teach entrepreneurship through traditional teaching practices in which the learner tends to be a passive recipient. Furthermore, since entrepreneurship education is about cross-curricular competencies, it is best if it is made available to all students and embedded in existing courses rather than treating it as a separate subject. This is especially true at the primary and secondary school levels [5].

A very effective tool for building entrepreneurship competences is the EntreComp model, designed by the European Commission, over a period of 18 months. The EntreComp framework was developed through a mixedmethods approach and proposes a shared definition of entrepreneurship as a competence in order to establish a bridge between the worlds of education and work. The EntreComp conceptual model "is made up of two main dimensions: the 3 competence areas that directly mirror the definition of entrepreneurship as the ability to turn ideas into action that generate value for someone other than oneself; and the 15 competences that, together, make up the building blocks of the entrepreneurship as a competence for all citizens" [2]. The 3 interrelated and interconnected competence areas are: "Ideas and opportunities", "Resources" and "Into action". The framework develops the 15 competences along an 8-level progression model and proposes a comprehensive list of 442 learning outcomes. The framework can be used as a basis for the development of curricula and learning activities fostering entrepreneurship as a competence and for the guidance of the efforts of teachers, policy makers, employers to develop and assess the competence of students, employees. In order to improve the way entrepreneurship education is made "researchers and educators should work together to design contents and methods incorporating these components in their teachings" [4].

In the following, we propose a general framework as a functional model, applicable for an interdisciplinary curricular approach in higher education. The elements presented below were conceived as recommendations for the West University of Timişoara in order to improve the policies in the field of entrepreneurship, but we consider that they are applicable and adaptable to any higher education institution. In order to successfully integrate entrepreneurial skills in each specialization offered by a higher educational institution it is necessary to implement a strategy that includes a series of general steps, which can be customized according to profile and specialization, but can certainly be applied (possibly after a prior adaptation) within different faculties.

A. Popularization of the EntreComp model among academics by conducting workshops / focus groups with university teachers for: 
1. Knowledge of the 3 areas of competence of EntreComp.

2. Knowledge of the 15 constituent elements of entrepreneurial competence.

3. Analysis of the 15 constituent elements of entrepreneurial competence in relation to the professional and transversal competences of study programs.

B. Introduction of entrepreneurial competences in the curriculae of various faculties and specializations by:

1. Identifying professional and transversal competences that can integrate the constituent elements of entrepreneurial competence or that can be optimized by integrating the constitutive elements of entrepreneurial competence.

2. Restructuring / optimizing the discipline syllabuses from the perspective of integrating the constitutive elements of the entrepreneurial competence.

3. Re-analyzing the syllabuses from the perspective of integrating the constitutive elements of the entrepreneurial competence and identifying the elements that are little or impossible to approach within the respective academic programs.

C. Implementation of teaching activities for the development of entrepreneurial skills

1. Designing and implementing extra-curricular activities that offer the possibility of training and practicing as a whole the competencies targeted by the EntreComp framework.

2. Designing and implementing teaching activities infused with entrepreneurial skills.

D. Implementing continuous training activities for university teachers in order to develop entrepreneurial skills. This could be the first element in the implementation of entrepreneurial education strategies in a broader sense. These activities for the professional and personal development of academics could be carried out in various forms (workshops, summer schools, etc.). Teachers who will participate in these activities will be aware of the importance of entrepreneurship education among students and will be open and interested in implementing elements of entrepreneurial skills in their own disciplines.

The added value elements of the strategy we propose are:

1. The infusional approach of incorporating entrepreneurial skills in the teaching process of various subjects.

2. Updating the syllabuses from the perspective of entrepreneurial competencies (from the perspective of teaching - learning - assessment).

3. Exploring the possibility of introducing modules dedicated to specific entrepreneurial education tailored to the needs of students.

4. Creating multi and interdisciplinary teams meant to design and implement non-formal education activities that develop entrepreneurial skills (extra-curricular activities that would develop the competences targeted by the EntreComp framework).

We strongly agree with other researchers in the field that state that "the benefits of entrepreneurship education are not limited to boosting start-ups, innovative ventures and new jobs. Entrepreneurship is a competency for all, helping young people to be more creative and selfconfident in whatever they undertake" [5].

\section{References}

[1]. Adam, S., "Models and Value Patterns which Shape the Academic Career Path. Case-study: West University of Timişoara”, https://www.ceeol.com/search/article-detail?id=732630, 2018, Retrieved 1st october 2020

[2]. Bacigalupo, M., Kampylis, P., Punie, Y., Van den Brande, G., "EntreComp: The Entrepreneurship Competence Framework". Luxembourg: Publication Office of the European Union; EUR 27939 EN; doi:10.2791/593884, 2016, Retrieved 1st May 2019

[3]. European Commission, "Towards Greater Cooperation and oherence in entrepreneurship education". Enterprise and Industry Directorate-General. ECOTEC: Brussels, Retrieved from http://ec.europa.eu/enterprise/ policies/sme/promotingentrepreneurship/ entrepreneurship/reflection-

panels/files/entr_education_panel_en.pdf, educationtraining-

Retrieved 30 october 2019

[4]. Fayolle, A., "Personal views on the future of entrepreneurship education. Entrepreneurship \& Regional Development", 25:7-8, 692701, DOI: $10.1080 / 08985626.2013 .821318, \quad 2013$, Retrieved 1st October 2020

[5]. Redford, D. T., "Entrepreneurial teacher training in Europe: an overview of European policies and developments". Journal for Educators, Teachers and Trainers, 2015, Vol. 6(2), pp. 17-34, Retrieved 1st October 2020.

\section{Acknowledgements}

This research was realized within the project START UP BANAT, POCU 103886. We thank Prof. Ph. D. Cosmin Enache, vicerector of the West University of Timisoara who provided insight and expertise that assisted the research, although he may not agree with all of the interpretations/conclusions of this paper.

\section{Personal Notes}

Ioana Gabriela Domilescu (graduate and doctor in educational sciences) is lecturer at the Teacher Training Department (DPPD) from the West University of Timisoara. Her main areas of interest are: Pedagogy (Introduction to the theory of education; Theory and methodology of the curriculum; Theory and methodology of instruction and Theory and practice of evaluation), Entrepreneurship education and Evaluation in higher education. She has extensive experience in pre-service teacher training and university teaching staff training programs and activities. Her recent published papers address the initial training of teachers in Romania in the context of European evolutions in the field.

Andrei Alexandru Tărăbîc (Ph.D. Candidate since 2016) from the West University of Timisoara. His main areas of interest are Entrepreneurhisp . 